\title{
Assessment of the Space Weather Effect on Human Health in the Arctic Zone Using the Example of Tiksi Settlement
}

\author{
Alena A. Strekalovskaya, $\mathrm{PhD}^{1^{*}}$; Palmira P. Petrova, $\mathrm{PhD}, \mathrm{ScD}^{1}$; \\ Kirill V. Komzin ${ }^{1}$; Larisa A. Malysheva, $\mathrm{PhD}^{1}$; Sergey N. Samsonov, $\mathrm{PhD}^{2}$; \\ Svetlana S. Parshina, $\mathrm{PhD}, \mathrm{ScD}^{3}$; Alla A. Andreeva ${ }^{4}$ \\ ${ }^{1}$ North-Eastern Federal University named after MK Ammosov, Yakutsk, the Republic of Sakha (Yakutia), Russia \\ ${ }^{2}$ Institute of Cosmophysic Researches and Aeronomy named after Yu.G. Shafer, Siberian Branch of the RAS, \\ Yakutsk, the Republic of Sakha (Yakutia), Russia \\ ${ }^{3}$ Medical University named after V.I. Razumovsky, Saratov, Russia \\ ${ }^{4}$ Bulunsky Central District Hospital, Tiksi, the Republic of Sakha (Yakutia), Russia
}

\begin{abstract}
In order to assess the space weather effect on the well-being and health of people with cardiovascular pathology in Arctic conditions, we carried out the processing and analysis of space weather parameters and the electronic database of patients with cardiovascular diseases at the Central District Hospital in Tiksi settlement (the Republic of Sakha (Yakutia) (RS(Y)). Patients visited the polyclinic or requested an ambulance because their health had deteriorated. As a result of our research, we found some conjunctions of trends in the change in geomagnetic disturbances (Kp-index) and the number of patients' visits to medical institutions for arterial hypertension (AH) in 2015, 2016 and 2017. It can therefore be concluded that geomagnetic disturbances have an impact on the cardiovascular system of a person living at high latitudes.(International Journal of Biomedicine. 2018;8(1):56-59.)
\end{abstract}

Key Words: cardiovascular diseases $\bullet$ arterial hypertension $\bullet$ space weather $\bullet$ geomagnetic activity $\bullet$ Arctic zone

\section{Introduction}

The effect of the environment on human health is one of the key issues at the present time. Apart from the obvious effects of certain environmental factors, such as meteorological parameters and social factors, it has been found that electromagnetic radiation, produced by electric and magnetic fields, which are not observed by human senses, can also have an effect on people's health. At the end of the last century, after the first flight of a spacecraft that measured the parameters of particle flows, electromagnetic fields, and radiation, there appeared an understanding of the interplanetary environment and how the fields, particles and radiation can reach a particular area of the interplanetary environment and have an effect on life on Earth. Moreover, at the beginning of our century the term "space weather" appeared. It refers to the interplanetary environmental conditions. The sun has

*Corresponding author: Alena A. Strekalovskaya, PhD. M. K. Ammosov North-Eastern Federal University. Yakutsk, the Republic of Sakha(Yakutia),Russia. E-mail: a_strekalovskaya@mail.ru the main impact on the interplanetary environment. Therefore, the identification of link mechanisms between solar activity and the functioning of the various objects of the biosphere, including humans, is one of the fundamental problems of modern science.

There are many published works about the effects of space weather on human health..$^{(1-19)}$ However, there are still many open questions about the specific parameters of space weather affecting the human body, and about the mechanisms of such influence.

At present, the pathogenesis of $\mathrm{AH}$ is being actively studied by the world's leading institutions. The Arctic zone is located in the territory most affected by the heliogeophysical factors of space weather because of its geophysical and atmospheric features. Within the framework of this research, it was planned to determine the presence or absence of a link between episodes of increasing blood pressure in $\mathrm{AH}$ patients and the periods of helio-geomagnetic agitations.

\section{Materials and Methods}


To research the dynamics of health deterioration among people having cardiovascular diseases living in high latitudes, we studied the electronic database of patients' visits to the medical institutions of Tiksi (the Bulunsky district of RS(Y)) between 2015 and 2017.

To define the reasons influencing the deterioration of health among patients with heart and vessel failures, we compared the visits for AH with the Kp-index (planetary index of geomagnetic disturbance), which is a measure of the level of geomagnetic storminess. For this purpose, we used the $\mathrm{Kp}$-index and the average monthly number of visits for $\mathrm{AH}$ to the medical institutions of Tiksi. The Kp-index reflects the average planet geomagnetic field deviation. It is measured in conditional units from 1 to 9 . The index rises as the intensity rises. For the statistical processing and plotting of data, we used the computer program Origin.

\section{Results and Discussion}

To analyze the effect of heliogeophysical factors on the health of people living in Tiksi settlement, the data from the ambulance and polyclinic service of the Bulunsky Central District Hospital were selected. For comparison, we chose the cases of deterioration in the well-being of people due to an increase in blood pressure in 2015, 2016 and the first 6 months of 2017. We then analyzed patients' visits and compared them with the Kp-index for the same period of time (2015, 2016 and the first 6 months of 2017). In general, during these years we can observe a reduction in the 11-year cycle of solar activity and a general decrease in geomagnetic disturbance.

The analysis of data on the number of cases of $\mathrm{AH}$ and the comparison with the Kp-index showed the following. In 2015 , there were 2,109 visits from patients diagnosed with $\mathrm{AH}, 1,416$ of them were women, and 693 men. Out of the total number of visits, $1,116 / 53 \%$ people were registered as dispensary for hypertension. In most cases (65\%), $\mathrm{AH}$ was observed in the elderly, 60 and older, which is quite logical, since the pathogenetic factors having an effect on the development of hypertensic crisis in the elderly are high: blood-circulating angiotensin II, damage to the vascular endothelium and a decrease in the allocation of vasodilating substances. Patients of middle age ( $<60$ years) constituted $740 / 35 \%$ of visits. Myocardial infarction was registered in 14 patients, stroke - in 29.

In 2015, there was a conjunction of the main changes in the $\mathrm{Kp}$-index and the number of visits of patients diagnosed with hypertension, which indicates a connection between these two parameters (Fig.1).

Figure 1 shows a graph of the dynamics of changes as well as the conjunctions of two main maximums - the spring and autumn months (March and September-October) of 2015. Thus, for example, the maximum conjunction of $\mathrm{AH}$ patients $(n=215)$ and the Kp-index was observed in March 2015, where the Kp-index of geomagnetic disturbance was 612.33. In September, the number of visits increased to 234, compared to the summer months of the year, and the Kp-index was 578.35.

In 2016, there were 2,425 cases of patients with hypertension, of which 1,606 were women and 819 were men.
As in 2015, the most cases of AH (62.8\%) were observed in the elderly from 60 years and older; middle-aged patients constituted 37.2\% - 900 people. Myocardial infarction was registered in 14 patients, stroke - in 30 .

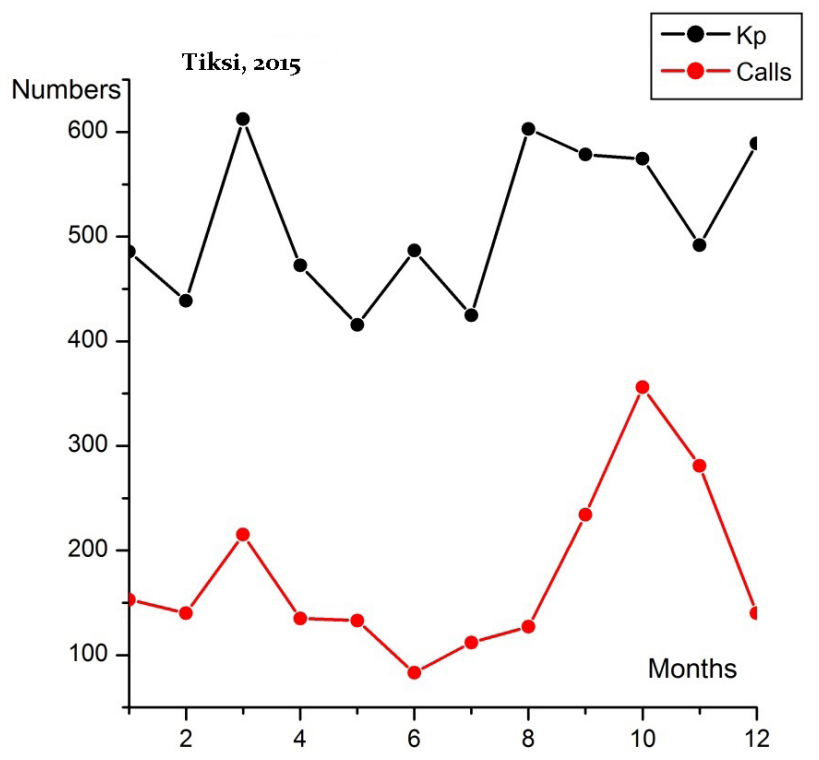

Fig. 1. Annual dynamics of the Kp-index and the number of visits of patients diagnosed with AH in 2015.

Figure 2 shows the annual dynamics of the geomagnetic disturbance index and the number of patients with hypertension in 2016: Early in the year, there was a conjunction in March, when the number of visits was 276 , and the $\mathrm{Kp}$-index was 502.0. Further, the trends of changes in the components of 2016 began to differ, which may happen because of the imposition of interferences and errors and, accordingly, it requires further detailed consideration and further research.

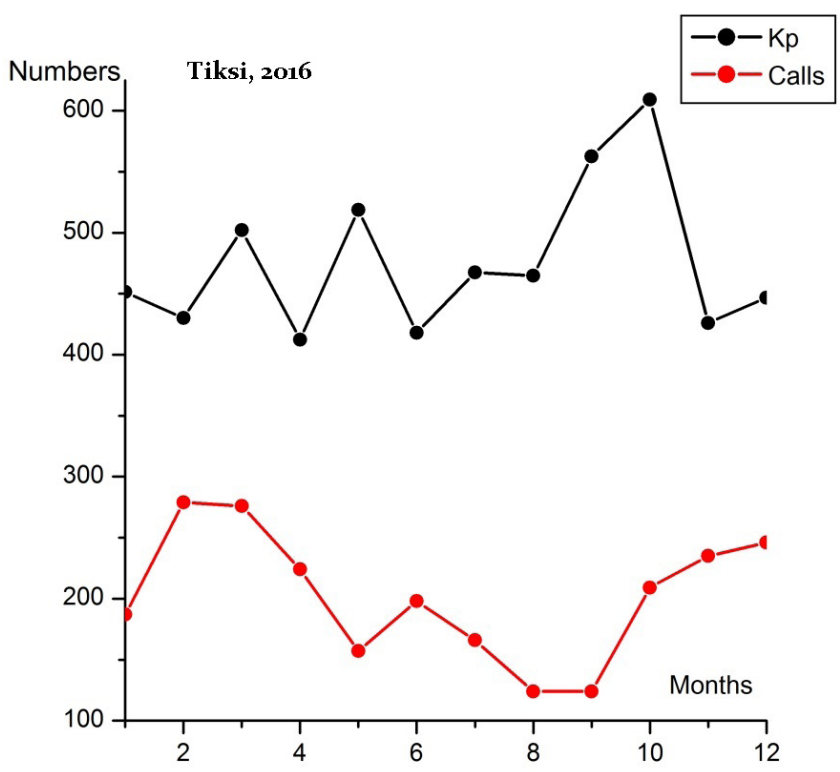

Fig. 2. Annual dynamics of the Kp-index and the number of visits of patients diagnosed with hypertension in 2016. 
For 6 months (January-June) in 2017, 998 patients were diagnosed with $\mathrm{AH}$, of whom 659 were women and 339 were men. This is slightly less than the number of $\mathrm{AH}$ cases during the same period of 6 months in $2015(\mathrm{n}=859)$, but significantly less than the 6 months period in $2016(\mathrm{n}=1321)$. Myocardial infarction was detected in 4 patients, stroke - in 15 .

As we have the medical data for only 6 months in 2017, the comparison with the $\mathrm{Kp}$-index showed a conjunction of the trend of changes in both parameters. Figure 3 shows that in March 2017, there was a conjunction of the maximum number $(n=238)$ of AH patients with the maximum of the Kp-index of geomagnetic disturbance, which was 567.67. Thereafter, from March to June, there was a conjunction of the dynamics of the Kp-index and the number of complaints about $\mathrm{AH}$ : The complaints were gradually reduced to a minimum in June 2017.

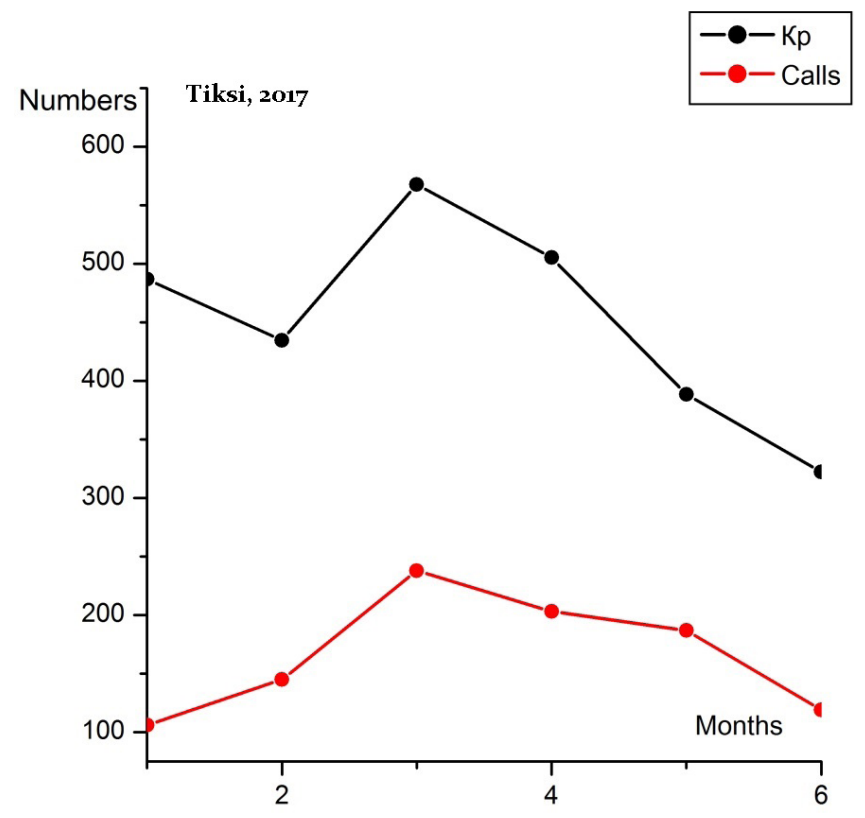

Fig. 3. Annual dynamics of the Kp-index and the number of visits of patients diagnosed with hypertension for 6 months in 2017.

Figure 4 shows daily data in 2015 , when the changes in the Kp-index and the number of patients' visits for hypertension were taken into account, in comparison with the sex and age of patients. In general, the figure shows an increase and decrease in geomagnetic activity per day during a whole year. The conjunction of the $\mathrm{Kp}$-index correlates with the increase in the number of applications from the older people $(65 \%)$ and from female patients $(\mathrm{n}=1416)$.

Figure 5 represents in more detail the data showing an increase in the Kp-index and the number of medical assistance visits for AH in February 2015. From the graph, we can see a conjunction of the medical data dynamics and geomagnetic disturbance data within one month. At the same time, the sex and age of patients seeking treatment in the Bulunsky Central District Hospital were also taken into account. Figure 5 shows that almost every change in geomagnetic disturbance affects people as an increase in blood pressure. The conjunction of the medical data dynamics and geophysical parameters indicates the effect of geomagnetic disturbance on the human cardiovascular system.

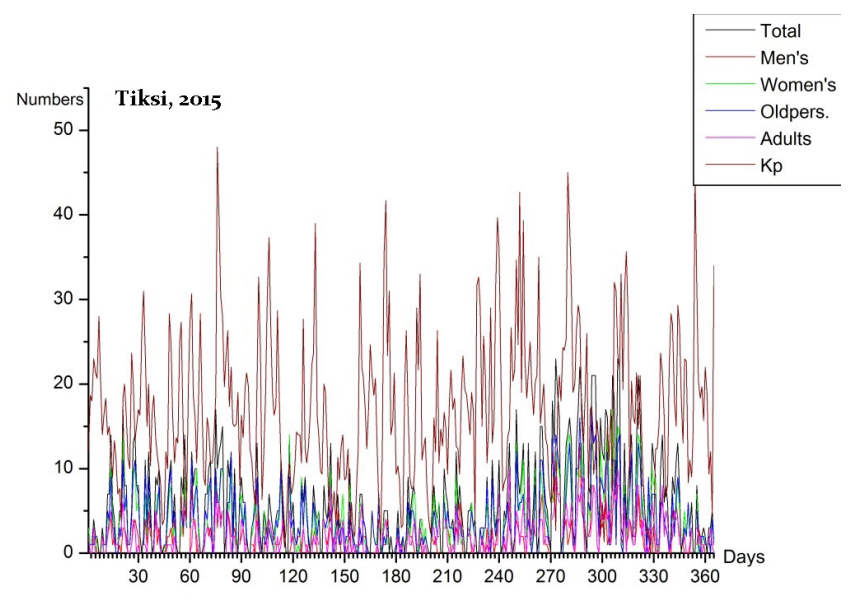

Fig. 4. Daily data of the Kp-index and the number of visits of patients diagnosed with AH in 2015. Note: the "adults" group corresponds to the average age according to the WHO classification (2017).

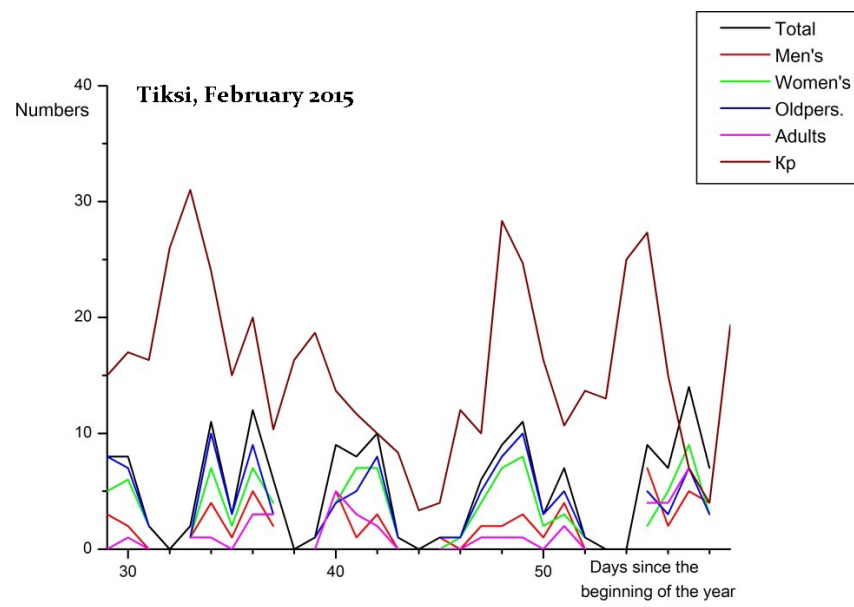

Fig. 5. Daily data of the Kp-index and the number of visits of patients diagnosed with AH in February 2015. Note: the "adults" group corresponds to the average age according to the WHO classification (2017).

\section{In conclusion:}

1. The conjunction of the maxima of the temporal change in the geomagnetic disturbance (Kp-index) and the number of patients' visits to medical institutions for AH in 2015 and 2017, as well as a partial conjunction in 2016, was determined. On this basis, we conclude that geomagnetic disturbances affect the cardiovascular system of a person living at high latitudes (the Arctic zone of the RS(Y)).

2. The increase in the number of visits for medical care for $\mathrm{AH}$ in different periods of a year correlates with the intensity of the Kp-index: The most active periods were the winter-spring in 2015, 2016 and 2017.

The article was prepared based on the results of the project "Assessment of the main trends in change of the natural and socio-economic status, human development of the Arctic 
Economic Zone of Yakutia" of the Program of Integrated Research in $\mathrm{RS}(\mathrm{Y})$ aimed at developing its productive forces and social sphere in the years 2016-2020.

\section{Competing interests}

The authors declare that they have no competing interests.

\section{References}

1. Vladimircky BM., Kislovskiy .D. Solar activity and the biosphere. Moscow: Knowledge; 1982. [in Russian].

2. Andronov TI, Deryapa NR, Solomatin AP. Heliometeotropic reactions of a healthy and a sick person. Leningrad: Medicine; 1982. [in Russian].

3. Sidyakin VG. Temuryants N, Makeev VB, Vladimircky BM. Space ecology. Kiev: Science Dumka; 1985. [in Russian]

4. Komarov FI, Breus TK, Rapoport SI, Oraevskiı̌ VN, Gurfinkel' IuI, Khalberg F, et al. [Biomedical effects of solar activity]. Vestn Ross Akad Med Nauk. 1994;(11):37-50. [Article in Russian].

5. Baevsky RM, Petrov VM, Cornelissen G, Halberg F, Orth-Gomer K, Akerstedt T, et al. Meta-analyzed heart rate variability, exposure to geomagnetic storms, and the risk of ischemic heart disease.. Scr Med (Brno). 1997;70(4-5):201-6. 6. Cornélissen G, Wendt HW, Guillaume F, Bingham C, Halberg F, Breus TK, et al. Disturbances of the interplanetary magnetic field and human pathology. Chronobiologia 1994;21:151-4.

7. Watanabe Y, Hillman DC, Otsuka K, Bingham C, Breus TK , Cornélissen G, Halberg F. Cross-spectral coherence between geomagnetic disturbance and human cardiovascular variables at non-societal frequencies. Chronobiologia. 1994;21(3-4):265-72.
8. Vladimirsky BM, Sidyakin VG, Temuryants NA, Makeev VB, Samohvalov VP. Space and biological rhythms. Simferopol: SGU; 1995. [in Russian].

9. Breus TK, Halberg G, Cornelissen G. [Effect of solar activity on the physiological rhythms of biological systems]. Biofizika. 1995 Jul-Aug;40(4):737-48. [Article in Russian].

10. Breus TK, Baevskiǐ RM, Nikulina GA, Chibisov SM, Chernikova AG, Pukhlianko M, et al. [Effect of geomagnetic activity on the human body in extreme conditions and correlation with data from laboratory observations]. Biofizika. 1998;43(5):811-8. [Article in Russian].

11. Lednev VV. [Bioeffects of weak static and alternating magnetic fields]. Biofizika. 1996;41(1):224-32. [Article in Russian].

12. Chibisov SM, Ovchinnikova LK, Breus TK. Biological rhythms of heart, and "external" stress. Moscow: Publishing House of The Peoples' Friendship University of Russia ; 1998. [in Russian].

13. Vladimirckiy BM, Temuryants NA. The impact of solar activity on the biosphere-noosphere. Moscow: MNEPU; 2000. [in Russian].

14. Yagodinsky VN. We are ruled by the space. Moscow: Ripol Klassik; 2003. [in Russian].

15. Breus TK, Rapoport SI. Magnetic storms: biomedical and geophysical aspects. Moscow; Soviet Sport; 2003. [in Russian]

16. Gurfinkel YuI. Coronary heart disease and solar activity. Moscow; IIKTS "Elf-3"; 2004. [in Russian].

17. Murtazov AK. Ecology of Near-Earth Space. Moscow:FIZMATLIT; 2004.[in Russian].

18. Kudryashov YuB, Perov YuF, Rubin AB. Radiation Biophysics. Moscow: FIZMATLIT; 2008. [in Russian].

19. Ragul'skaya MV, Rudenchik EA, Chibisov SM, Gromozova EN. Effects of Space Weather on Biomedical Parameters during the Solar Activity Cycles 23-24 Bull Exp Biol Med. 2015 Jun;159(2):269-72. doi: 10.1007/s10517-015-2939-0. 